\title{
DETERMINANTS OF SYMBOLIC INFERENCES ABOUT ORGANIZATIONS AMONG JOB MARKET ENTRANTS
}

Erin E. Thornbury

\begin{abstract}
A Dissertation
Submitted to the Graduate College of Bowling Green

State University in partial fulfillment of the requirements for the degree of
\end{abstract}

\section{DOCTOR OF PHILOSOPHY}

DECEMBER 2006

Committee:

Scott Highhouse, Advisor

Nancy Fordham

Graduate College Representative

Yiwei Chen

Steve Jex 


\begin{abstract}
Scott Highhouse, Advisor

Previous research has shown that organizational reputation can have an important impact on recruitment and retention, but little is known about the organizational factors that differentiate between an organization with a positive symbolic reputation and one with a negative symbolic reputation. Research has begun to examine the antecedents of attraction, but these studies have typically viewed reputation as a unidimensional construct, whereas the present study examines the symbolic reputation factors of organizational impressiveness and respectability, and have primarily focused on reputation perceptions of financial and business experts, while this study focuses on the perceptions of naïve, first-time job seekers. Results indicate that naïve job seekers view organizations that advertise heavily to be most impressive, and view organizations with products perceived to be high-quality as the most respectable. Implications for recruitment are discussed.
\end{abstract}


TABLE OF CONTENTS

Page

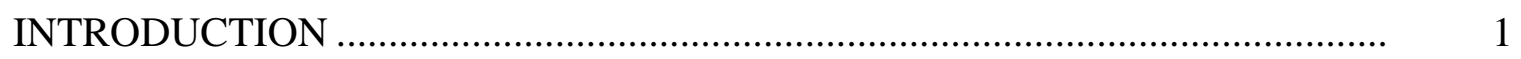

Importance of Symbolic Attraction................................ 2

Symbolic Reputation: Impressiveness and Respectability............... 4

Social Adjustment: Impressiveness ................................................. 4

Value Expressive: Respectability...................................................... 6

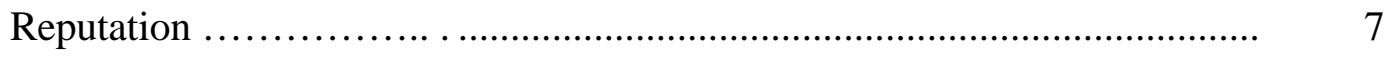

Present Study: Constructs ............................................................... $\quad 10$

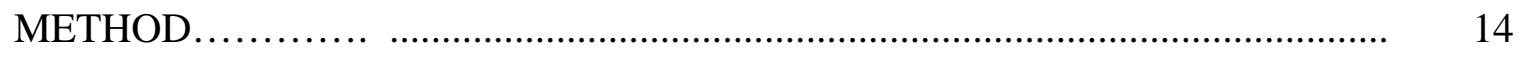

Dependent Variable.................................................................... 14

Objective Signals....................................................................... 15

Revenue and Advertising Budget ......................................... 15

Charitable Donations .............................................................. 15

Media Attention ................................................................... 16

Stock Price ........................................................................ 16

SEC Filings .................................................................. 16

Business Ethics ................................................................. 17

Fortune ....................................................................... 17

Product Quality and Value ...................................................... 17

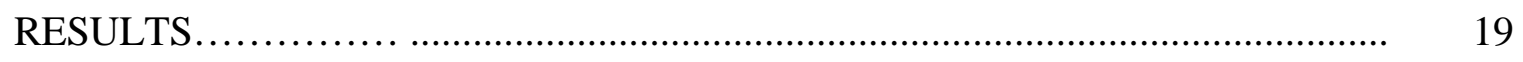

Preliminary Analyses ................................................................... 19 
Descriptive and Scale Statistics: Original Scale .......................... 19

Primary Analyses ...................................................................... 20

Multiple Regression: Original Scale .......................................... 20

Multiple Regression: Unidimensional Symbolic Reputation Measure 22

Multiple Regression: Revised Scales ........................................ 22

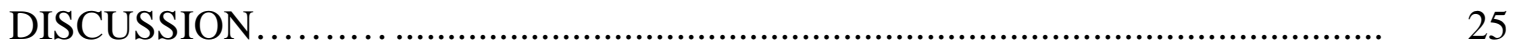

Impressiveness....................................................................... 25

Revenue ........................................................................ 25

Media Attention .................................................................... 26

Advertising ......................................................................... 26

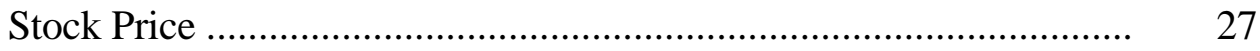

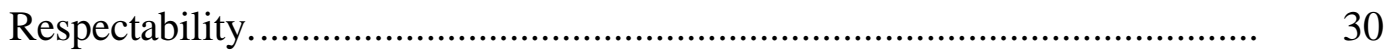

Responsibility to Community ............................................... $\quad 30$

Charitable Donations ....................................................... $\quad 30$

Business Ethics Rank ................................................... $\quad 30$

Responsibility to Employees ....................................................... 31

Fortune Magazine Ranking ........................................... 31

SEC Violations ............................................................. 31

Responsibility to Consumers .................................................. $\quad 30$

Product Quality .......................................................... $\quad 30$

Product Value ................................................................... $\quad 30$

Dimensionality of Symbolic Reputation............................................... 32

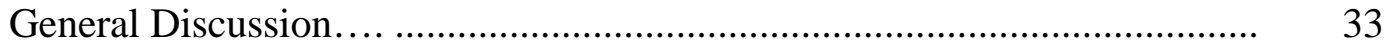


Limitations and Future Research..................................................... 33

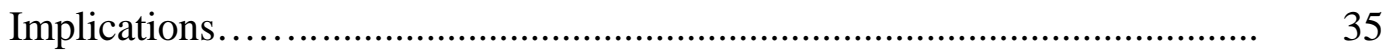

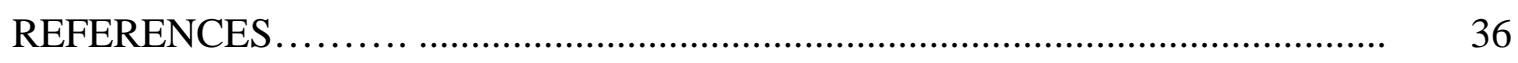

APPENDIX A. IMPRESSIVENESS AND RESPECTABILITY SCALE .............. 40

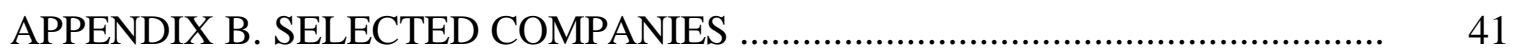

APPENDIX C. PRODUCT QUALITY AND VALUE SCALE.......................... 42 


\section{LIST OF TABLES}

Table

Page

1 Summary of Previous Reputation Determinants......................................

$2 \quad$ Proposed Model of Constructs Underlying Symbolic Reputation.................... 44

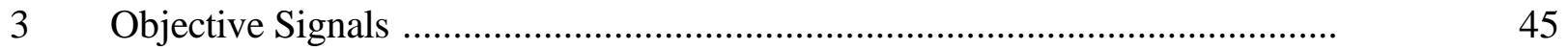

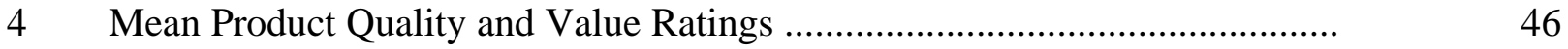

$5 \quad$ Mean Impressiveness and Respectability Scores: Original Scale .................... 47

$6 \quad$ Signal Correlations ......................................................................

$7 \quad$ Impressiveness Beta Weights and Correlations .........................................

$8 \quad$ Respectability Beta Weights and Correlations ....................................... 50

$9 \quad$ Exploratory Impressiveness Beta Weights and Correlations ......................... 51

10 Unidimensional Symbolic Reputation Beta Weights and Correlations ........... 52

11 Signal Correlations: Revised Scale ............................................... 53

12 Mean Impressiveness and Respectability Scores: Revised Scale ................. 54

13 Revised Impressiveness Beta Weights and Correlations .......................... 55

14 Revised Respectability Beta Weights and Correlations ............................. 56 


\section{LIST OF FIGURES}

Figure

Page

1 Relationship Between Market Signals, Symbolic Inferences, and Attraction........... 57 


\section{INTRODUCTION}

Determinants of Symbolic Inferences about Organizations among Job Market Entrants

We spend a sizable portion of our lives at work, and it stands to reason that where we work forms an important part of our identity (Scott \& Lane, 2000). In addition to the obvious tangible benefits such as pay, we also derive psychological benefits from associating with companies. Organizational membership can provide a venue for expressing core values and obtaining approval from esteemed others (Highhouse, Thornbury, \& Little, in press). Having a positive reputation provides a competitive advantage for organizations attempting to recruit the best and brightest applicants. However, not all organizational reputations are created equal. Some companies are perceived to be trustworthy, whereas others may be seen as dishonest. Some may be seen as innovative, while others may be seen as stodgy (Slaughter et. al., 2004). What distinguishes an organization that an applicant would be proud to work for and identify with from a less reputable one?

The present study aims to identify the important organizational characteristics that signal reputation to naïve, or entry- level job seekers. Highhouse et al. (in press) presented a theory of symbolic attraction to organizations that provides the foundation for the present study. According to this theory, symbolic reputation is comprised of non-tangible inferences people make about a company. Two primary foci of this theory are inferences about the impressiveness and respectability of organizations. The present study is concerned with identifying what signals impressiveness and respectability to new job-seekers, and will explore the relationship between market signals and the symbolic inferences made about organizations. Figure 1 illustrates the relationship between market signals, symbolic inferences, and employer attraction that forms the basis of the theory of symbolic attraction presented by Highhouse et al. (in press). Although the 
specific market signals and inferences (such as 'dominant' or 'fair and ethical') will differ somewhat in the present study, this figure illustrates the process by which inferences are made and shows the importance of symbolic inferences about impressiveness and respectability to organizational attraction.

Importance of Symbolic Attraction

Lievens and Highhouse (2003) borrowed from marketing research on brand image the notions of symbolic and instrumental factors. In a brand image context, instrumental factors consist of objective product attributes such as price and quality. Symbolic factors are intangible characteristics, perceptions, or traits ascribed to a product, such as 'conservative' or 'trendy' (Keller, 1993). In an organizational context, Lievens and Highhouse (2003) applied the same framework to explain organizational attraction. In this context, instrumental factors are inferred from job or organizational attributes such as pay, flexibility, and bene fits. Symbolic factors are traits ascribed to an organization, such as trendy or conservative. Just as traits are ascribed to brands or products, research has shown that people also attribute traits such as "trendy" to companies during the recruitment process (Lievens \& Van Hoye, 2005; Slaughter, et. al, 2004). Lievens and Highhouse (2003) found that symbolic trait inferences about an organization added incremental variance over instrumental attributes such as pay in predicting organizational attraction in their study of Belgian banks. More recently, Lievens and Van Hoye (2005) found that symbolic trait inferences such as prestige or excitement accounted for the largest amount of variance in predicting attraction to military organizations.

Other research has evaluated the impact of symbolic factors, over and above the effect of instrumental factors, on job choice. In a study designed to identify components of company employment image in the fast-food industry, Highhouse, Zickar, Thorsteinson, Stierwalt and 
Slaughter (1999) evaluated the dimensions that differentiated the likelihood of working for one fast-food establishment over another for both high-school students and retirees. The results indicated that symbolic factors such as atmosphere, hearsay, product image, and respectability were among the most important factors when deciding among job opportunities. These factors were more predictive than instrumental or job characteristics such as work variety, hours, and coworkers. Though it is important to keep in mind that these were factors used to differentiate between similar jobs in the same industry, the factors that were found to be most significant were features often associated with pre-recruitment reputation. More specific attribute (instrumental) information, such as hours, coworkers and work variety was found to be less predictive of corporate employment image in the Highhouse et al. study. Collins and Stevens (2002) found that exposure to early recruitment information such as advertising, sponsorship, and word of mouth endorsements, particularly for highly publicized companies, increased both attraction to the organization and perceptions of the job attributes of the position they were considering.

There is evidence to support the proposition that a positive symbolic reputation can be beneficial to the organization beyond simply attracting applicants. Cable and Turban (2003) found that job seekers were willing to accept approximately seven percent less in salary from organizations with positive reputations than at an identical position at an organization with a negative reputation. During the recruitment process, and particularly during the initial attraction phase, job-seekers, and particularly first-time job seekers, may have limited information abut the attributes of the job. An organization's reputation can be used as a signal about organizational attributes, and the job attributes at organizations with positive reputations are perceived to be better than the attributes at organizations with negative reputations (Cable \& Turban, 2003). However, the opposite relationship between organizational attributes and reputation is equally 
important. The current study is concerned with the symbolic nature of reputation, and more specifically, how the symbolic reputation factors of impressiveness and respectability are signaled to job seekers. The theory of symbolic attraction provides an explanation as to why symbolic reputation is important to job seekers.

Symbolic Reputation: Impressiveness and Respectability

Highhouse et al. (in press) examined the concept of social identity consciousness, which examines the different symbolic factors job seekers attune to, based on the value they place on different aspects of social identity (Figure 1). The goal of this research was to illustrate how attraction to an organization is functional, in that it allows us to express core values and provides an opportunity for gaining social approval and acceptance (Katz, 1960). Through scale

development and a series of validation studies, the authors identified two important concerns that appear to underlie social-identity consciousness: social adjustment (concern with impressiveness) and value expressiveness (concern with respectability). Associating with a company can provide an opportunity for gaining social approval from others via organizational membership (social adjustment), or provide an outlet for expressing values by associating with companies widely believed to be 'good' or reputable (value-expression). Impressiveness and respectability were found to be the important subdimensions of symbolic reputation.

\section{Social Adjustment: Impressiveness}

Social-adjustment concerns represent a job seeker's desire to impress others through an association with an impressive, prestigious, or high-status organization. Thus, the perceived impressiveness of an organization is an important component of organizational attraction. Those who scored high on the social adjustment dimension of social identity consciousness expressed concern about the impressiveness or prestige of a potential employer in the eyes of others (i.e. 
family, friends, or strangers). Through understanding the underlying desire to impress others, it becomes clear that identifying with an organization that relevant others deem impressive is a viable way to fulfill this self-presentation need. Other research has also found that the perceived impressiveness of an organization can have an impact on organizational attraction. Research that evaluates the concept of "basking in reflected glory" has found that people tend to choose to identify with teams, organizations, or groups that are successful (Cialdini et al., 1976). For example, one study found that the level of organizational identification, or the extent to which an employee identifies with the organization he or she works for, is related to the perceived attractiveness of the organization's reputation (Dukerich, Golden, \& Shortell, 2002).

The most qualified job applicants will have a range of employment opportunities from which to choose, and may be attracted to an organization with the most prestigious or impressive symbolic reputation (Turban \& Cable, 2003). Highhouse, Lievens, and Sinar (2003) found a correlation of .40 between perceptions of an organization as prestigious and attraction to that organization as an employer, and a correlation of .44 between prestige and intentions to pursue employment with the organization. Dutton, Dukerich, and Harquail (1994) found that organizational members who reported a high level of perceived external prestige (extent to which he/she feels that outsiders hold the organization in high regard) also reported higher levels of organizational identification. Highhouse et al. (in press) found that impressiveness accounted for incremental variance above instrumental factors (location, benefits, and opportunity for promotion) in predicting organizational attraction. The degree to which one perceives his or her organization as impressive is an important symbolic aspect of image as an employer, and can fulfill important self-presentation needs. A second important factor is the extent to which membership in an organization allows you to express your central values. 


\section{Value Expressive: Respectability}

Value-expression concerns represent a job seeker's desire to express his or her central values through membership in an organization that is considered to be respectable or trustworthy. People who scored high on the value expressiveness dimension were most likely to endorse items concerned with the reputation of the potential employer as one that is respectable and honorable, and were concerned with scandal and social responsibility in relation to prospective employers (Highhouse et al., in press). People who scored high on the value-expressive dimension are expressing an underlying need to associate with an organization that is viewed positively by others.

The degree to which an organization is able to maintain an honorable reputation has been found to be an important symbolic component of organizational reputation (Montgomery \& Ramus, 2003). The value-expressive component of the social identity consciousness scale Highhouse et al. (in press) measures the importance of working for an organization that is scandal-free and has an honorable reputation in the community. Research evaluating the impact of organizational honor on outcomes such as attraction or satisfaction is limited, but the existing research indicates that being part of an honorable organization you can be proud of has an impact on a wide range of behaviors and attitudes. One study examining the effect of values on organizational commitment found that pride in the organization accounted for $66 \%$ of the variance in commitment (Knoop, 1994). Research has found that the public is becoming increasingly concerned with an organization's level of "corporate social responsibility" (Lewis, 2001). Other research has found that corporate social performance was positively related to reputation and to attractiveness as an employer (Turban \& Greening, 1996). Montgomery and Ramus (2003) found that the reputation (good vs. bad) of an organization was an important 
consideration for new MBAs. An organization's stance on ecological issues positively influenced perceptions of organizational attractiveness and increased likelihood of accepting a job offer with the organization (Bauer \& Aiman-Smith, 1996).

The present study is concerned with identifying the specific attributes or characteristics that differentiate organizations that are perceived to be high or low in impressiveness and respectability, and thus signal impressiveness or respectability to entry level job seekers. In other words, what are the things that lead to inferences that a company is impressive or respectable? Policy capturing research that has examined the impact of symbolic reputation factors on attraction to an organization has shown that impressiveness and respectability can predict attraction incrementally over the traditional instrumental attributes Highhouse et al. (in press).

\section{Reputation}

Although no research to date has explicitly examined the signals of impressiveness or respectability, recent research has begun to explore the antecedents of overall organizational reputation, (Fombrun \& Shanley, 1990; Cable \& Graham, 2000), and has identified factors that influence reputation perceptions. Despite the fact that this research (summarized in Table 1) explores reputation as a unidimensional construct, it provides an invaluable starting point for understanding what factors may lead to symbolic inferences.

Fortune magazine's list of the most admired companies provides some insight into the factors industry insiders consider most important in an organization's reputation. Companies are ranked on quality of management, quality of products or services, value as a long term investment, innovativeness, soundness of financial position, ability to attract, develop, and keep talented people, responsibility to the community and environment, and wise use of corporate assets (Brown \& Perry, 1994). Rankings are determined by averaging the ratings given by 
experts around the world for the eight categories. However, despite the fact that eight factors are considered in the Fortune rankings, research has found that these rankings are highly influenced by prior financial performance, rather than by a thorough comparison of the eight factors (Fombrun \& Shanley, 1990), making a clear understanding of the factors that affect reputation rankings difficult. Fombrun (1996) has also developed a reputation measure, known as the Reputation Quotient (RQ), that assesses six dimensions of an organization's reputation: vision and leadership, emotional appeal, financial performance, workplace environment, social responsibility, and products and services. RQ data are collected worldwide by conducting interviews and focus groups to assess perceptions of the six dimensions for visible organizations. Cable and Graham (2000) conducted a series of studies to examine the determinants of employer reputation for job seekers. Cable and Graham found that the industry in which the firm operates, opportunities for employee development, orga nizational culture, familiarity with the organization, the length of time the organization has been in existence, the size and location of the organization, workforce demographics, pay level, and the profitability of the organization all affected reputation perceptions. Although this research is distinctive in that is it one of the first to examine the factors that influence the perceptions job seekers hold of companies, it has important limitations. Their research relies solely on job-seekers' perceptions of the organizational attributes (culture, profitability, etc.), and does not compare those perceptions with actual data from the organizations. It is possible that general biases (halo) influences responses to such measures. It also assumes that reputation is a unidimensional construct. To address these issues, the present study will use both objective measures (signals of reputation) and subjective measures of reputation (ratings) for both impressiveness and respectability. 
Another study that examined the antecedents of reputation used objective data, but also conceptualized organizational reputation as a one dimensional factor. Fombrun and Shanley (1990) found that the sector in which the firm operates, size of the organization, economic performance, riskiness, level of institutional stock ownership, media exposure, advertising, and charitable expenditures all affected perceptions of reputation. This study found that financial performance measures had the strongest impact on reputation perceptions. It should be noted, however, that the measure used to assess reputation was adapted from the Fortune magazine rankings, a measure that is itself highly weighted towards financial reputation.

Other factors that may influence reputation include the recruiting sources that the company uses, as well as the visibility of the organization. The companies with the most positive reputations are often the most visible companies, and one of the best ways of staying visible is with an effective advertising campaign. The organizations that focus on advertising during times of crisis are often those who are able to repair their reputation most effectively (Dobson, 2005; Brady, Arndt, \& Barrett, 2005). In addition to media coverage, another way of staying visible is through having a well-known representative of the organization; a strong, visible CEO has been found to be an important component of reputation (Park \& Berger, 2004). The industry in which the company operates has also been shown to affect the reputation of an organization (Cable \& Graham, 2000).

In a study of the factors that influence Australian business journalists' perceptions of an organization's reputation, Dowling (2004) found that social accountability (corporate ethics and citizenship), corporate capability (leadership, innovativeness, financial performance), media relations (accessibility), market presence (familiarity, sector leadership), and corporate 
personality (how exciting, interesting, or 'Australian' the organization is perceived to be) were the most important determinants of reputation.

Finally, the organization's environmental stance (Bannerjee, Gulas, \& Iyer, 1995; Bauer \& Aiman-Smith, 1996; Turban \& Greening, 1996), history of scandal, labor relations (Turban \& Greening, 1996), and charitable donations/community activism (Turban \& Greening, 1996) have been linked to attraction to an organization and are likely to affect perceptions of a company's reputation.

The reputation research reviewed above provides an important first step in understanding the signals of impressiveness and respectability. However, rather than exploring reputation as a unidimensional construct as prior research has, the present study focuses specifically on the symbolic determinants of attraction. Knowing the specific organizational attributes that distinguish a high impressiveness organization from a low impressiveness organization, or an organization that is perceived to behave responsibly from one that is seen as less respectable, is the next step in developing a theory of symbolic reputation. For example, what information do entry-level job seekers consider when deciding whether a potential employer is honorable (thus fulfilling their need for value expression) or impressive (fulfilling the social adjustment needs)? Present Study: Constructs

Although an emerging body of research is exploring the importance of corporate reputation on attraction, far less attention has been devoted to discovering how reputation perceptions are formed. Research that has examined the impact of reputation factors on attraction to an organization has shown that symbolic attributes may play a significant role and predict attraction incrementally over traditional instrumental attributes. Previous research has identified two important dimensions of symbolic reputation: the impressiveness of the organization, and 
the level of respectability associated with the organization (Highhouse et al., in press). The goal of the present research is to identify the predictors of symbolic reputation, and to explore the congruence between the perceptions we hold about well-known companies' symbolic reputations, and the characteristics of the organizations that support or contradict these assumptions. For example, if an organization is perceived to be highly respectable, is this perception of respectability reflected in the organization's environmental practices, charitable giving, worker treatment, or history of scandal?

To facilitate this process and clarify the components of symbolic reputation presented in previous research, a model that specifies the antecedents of symbolic reputation is proposed (Table 2). For both impressiveness and respectability, the model presents the hypothesized constructs as well as the organizational characteristics presumed to act as signals. Drawing upon the components of symbolic reputation presented in previous research (summarized in Table 1) that are relevant to an organization's perceived impressiveness, two main categories emerge for which objective data (market signals) can be obtained: an organization's financial performance, and the visibility of the organization.

One of the factors underlying impressiveness is visibility. For an organization to be perceived as impressive or prestigious, it should be well-known (it would be difficult, if not impossible, for an outsider to be impressed by an organization he or she has never heard of). The American Heritage dictionary defines impressiveness as: "making a strong or vivid impression; striking or remarkable" (Pickett, 2000). To make an impression, an organization must be memorable and therefore highly visible. It is hypothesized that organizations with a higher level of visibility will be perceived as being more impressive than organizations with low visibility. Organizational impressiveness or prestige may be related to conceptualizations of status and 
popularity in other disciplines. Social impact (visibility) is often viewed as one of the most important subcomponents of status (Lease, Musgrove, \& Axelrod, 2002), and it stands to reason that visibility would also be one of the most important dimensions of impressiveness in an organizational setting.

Drawing upon previous research, visibility is operationalized by two factors: the level of advertising engaged in by the organization, and media attention. Previous research has found that advertising is one of the most effective strategies for increasing visibility of an organization (Dobson, 2005; Brady, Arndt, \& Barrett, 2005), and objective media attention (a measure of how often an organization is mentioned in the news) is also expected to be an important signal ofan organization's visibility (Fombrun \& Shanley, 1990; Dowling, 2004).

The second major construct underlying impressiveness is financial performance. Previous research has consistently found that financial performance is linked to an organization's reputation (Fombrun \& Shanley, 1990; Cable \& Graham, 2000). Superior financial performance indicates dominance in the industry, and dominance has often been linked to impressiveness (Lease, Musgrove, \& Axelrod, 2002). It is hypothesized that impressive financial performance will be signaled by an organization's stock price (Cable \& Graham, 2000; Brown \& Perry, 1994), as well as its overall revenue (Cable \& Graham, 2000; Brown \& Perry, 1994), with higher financial performers viewed as more impressive than lower financial performers.

A conceptual model is also proposed for the second symbolic reputation factor, respectability. A respectable organization that fulfills value-expressive needs can be viewed as a company that has an all around image as being a good or honorable organization. A respectable company can thus be conceptualized as one that behaves responsibly towards all of its relevant constituents: the community at large, employees, and the organization's consumers or customers. 
Table 2 outlines the organizational attributes, behaviors, and perceptions that are believed to signal these components of respectability.

The first, responsibility toward the community at large, indicates that the organization is concerned with more than financial gain, and hopes to make a positive impact on the community. An organization's ranking on Business Ethics magazine's list of the "100 Best Corporate Citizens" is hypothesized to be one important indicator of responsibility to the community. The Business Ethics rankings are compiled by taking expert ratings of companies that are seen as behaving responsibly and ethically towards their constituents. In addition, a company's level of charitable donations (Turban \& Greening, 1996) is also expected to contribute towards perceptions that a company behaves responsibly towards the community. Positive labor relations, or behaving responsibly towards employees, is also an important component of being a respectable organization (Dowling, 2004). An organization's ranking on Fortune magazine's list of the best companies to work for is one important indication of responsibility to employees. The number of SEC violations an organization has received is likely to negatively affect reputation perceptions (Turban \& Greening, 1996).

Finally, it is hypothesized that a respectable organization also behaves responsibly towards its consumers by providing them with goods or services that are safe, high-quality, and fairly priced. It is predicted that responsibility to consumers will be signaled by consumer ratings of the quality and value of the products each of the companies provide. These rankings will be modeled after the J.D. Power rankings, which are based on consumer ratings of the quality of products and services, or the Consumer Digest Best Buy rankings, which are used to indicate products that are an excellent value for consumers. 


\section{METHOD}

\section{Dependent Variable}

Forty-one current job-seeking graduating seniors (mean age $23,81 \%$ female), drawn from two upper-level psychology courses, provided impressions of organizational respectability and impressiveness. Only graduating seniors were asked to provide impressiveness and respectability ratings; this sample was chosen because they are actively pursuing employment opportunities and have a vested interest in the job-choice process.

The job seekers were presented with a series of items designed to assess their perceptions of the impressiveness and respectability of each company (Appendix A). The items were adapted from Highhouse et al.'s (in press) measure of social identity consciousness. The original scale was designed to measure job seekers' desire for employers that are impressive and/or respectable. The items used in the present study were adapted to measure perceptions of organizational impressiveness and respectability. For example, in the original scale (Highhouse et al., in press), the item "I wonder if strangers would be impressed by where I work" was used to assess a desire for an impressive employer. In the present study, the item was changed to "Strangers would be impressed if employees of this company told them where they work" to assess perceptions of organizational impressiveness.

For the impressiveness and respectability rankings to be meaningful, it was necessary to select companies that are familiar to job-seekers. Thus, the companies were selected from Harris Interactive's Annual RQ (Reputation Quotient) listing of the sixty most visible companies in America (www.harrisinteractive.com). This list is compiled using interviews conducted with the general public in which respondents are asked to nominate organizations with the best and worst reputations. In-depth interviews are conducted to assess reputation perceptions, and each 
organization was given a 'reputation quotient' score. Companies with both positive and negative reputations (high and low reputation quotient scores) were selected from within this list to allow variability in the impressiveness and respectability ratings. Reputation quotient scores ranged from 79.69 to 61.01. See Appendix B for a complete list of companies chosen and their corresponding reputation quotient scores. Participants were asked to rate their level of familiarity with each organization, and impressiveness and respectability ratings were excluded from analyses if participants indicated they were unfamiliar with a company.

To minimize fatigue and decrease the likelihood of careless responding, the list of companies was split in half, and each participant completed impressiveness and respectability scales for half of the thirty-one companies. To decrease the likelihood of order effects, the scale packets (each consisting of half of the companies) were presented in two randomly determined sequences, for a total of four different impressiveness and respectability packets.

\section{Objective Signals}

To examine the determinants of symbolic reputation, objective measures were obtained for each of the signals hypothesized to underlie reputation perceptions for each company. See Table 3 for the values of objective signals for each of the organizations. All financial data (advertising, revenue, and charitable donations) for foreign-based companies were converted into dollar amounts to ensure consistency.

\section{Revenue and advertising budget}

Revenue and advertising budget were found using information on the balance sheets made available for all publicly traded companies. Full-year 2005 financial data were used for each of the companies.

\section{Charitable Donations}


Unlike revenue and advertising budget, corporations are not required to disclose their charitable donations. However, total donation figures were made available for twenty-six of the companies. All information was obtained from balance sheets and corporate websites, and full year 2005 financial data were used.

Media Attention

An objective measure for media attention was obtained by counting the number of 'hits' for each company name using the search engine Google's news feature (http://news.google.com/nwshp?hl=en\&tab=wn\&q=). The news feature consolidates reports from thousands of worldwide news sources. Using this feature rather than counting all 'hits' from a general search engine eliminates extraneous or non news-related sources, and this feature provides a far broader and more accurate picture of the total media attention a company receives than examining a single news source would provide. Fombrun and Shanley (1990) also used a measure of media attention in they study of corporate reputation. In this research media attention was conceptualized as the total number of news stories about a given organization in a year. The authors did not indicate how news stories were compiled, and which sources were considered news sources.

Stock Price

Stock price for each company was obtained from the closing New York Stock Exchange (NYSE) price listed on May 22, 2006.

\section{SEC Filings}

The number of SEC filings was determined by searching for each company using EDGAR online (http://www.sec.gov/edgar.shtml), which consolidates all SEC filings for publicly traded companies. 


\section{Business Ethics}

The Business Ethics rankings, which are rankings of companies experts perceive to be serving all of their stakeholders with a high level of integrity, were taken from the most recent annual ranking (Raths, 2006). Because the companies selected for this list were all considered highly ethical and the differences between ethics scores among companies included was small, specific rank on the list was not used; rather, an organization's presence or absence on the list was taken into account.

\section{Fortune Magazine’s “Best Companies to Work For”}

The rankings for the companies that appear on Fortune Magazine's "Best Companies to Work for" were drawn from Fortune’s 2005 ranking (Levering \& Moskowitz, 2005). The rankings of the best companies to work for are based on the opinions of Fortune magazine, as well as employee ratings of organizational credibility, respect, fairness, and pride/camaraderie. As was the case with the Business Ethics rankings, and organization's presence or absence on the Fortune list was used for analyses.

\section{Product Quality and Value}

Finally, the ratings of the products and services offered by each of the companies were collected by asking a sample of consumers $(n=83)$ to rate the quality and value of the products or services offered by each of the companies (see Appendix C for questions). Although these are subjective ratings, unlike the objective measures used as signals for the other constructs hypothesized to underlie impressiveness and respectability, there are no true objective ratings of product value and quality. The only available sources of product value and quality ratings are those given by the consumer. Consumer web sites, such as Consumer Digest and JD Powers, only provide ratings for companies operating in a limited number of sectors, and primarily 
provide ratings by product rather than by company. To minimize bias, participants ranking the quality and value of the products and services offered by each of the companies did not rate the companies on impressiveness and respectability. The sample of eighty-three consumers was drawn from undergraduate psychology classes (mean age 20, $85 \%$ female) and were asked to rate the quality and value of the products and services offered by each of the companies. Average ratings for the quality and value of the products offered by each company can be seen in Table 4 . 


\section{RESULTS}

Preliminary Analyses

Descriptive and Scale Statistics: Original Scale

Intercorrelations among all of the independent and dependent variables can be found in Table 6. Most of the objective signals are uncorrelated. However, although corporations' charitable donations did not correlate with impressiveness or respectability ratings, they did correlate with objective media attention, revenue, and Fortune Magazine's "Best Companies to Work For" ranking. It is also notable that revenue is not significantly correlated with stock price, or with advertising budget. The impressiveness and respectability scales are highly correlated (.77) with one another. Because of this intercorrelation, the data were analyzed three ways: with the original scale, with impressiveness and respectability combined to create a unidimensional image score, and with a revised scale to reduce the intercorrelation between impressiveness and respectability.

Average impressiveness and respectability ratings (original scale) for each of the organizations can be found in Table 5. Sears/K-Mart Corporation was eliminated from analyses due to incomplete information. ${ }^{1}$ The t-values reported in Table 5 are used to indicate whether an organization's impressiveness and respectability ratings significantly differed from one another. To correct for experiment wise error, a 99.9\% confidence interval was used. Impressiveness and respectability scores differed significantly for $53 \%$ of the companies. Among the companies with significant differences between impressiveness and respectability, $69 \%$ of the companies scored higher on impressiveness than respectability, and $31 \%$ were viewed as more respectable than impressive. Reliability analyses were conducted on the impressiveness and respectability scales,

\footnotetext{
${ }^{1}$ Sears and K-Mart recently merged, and full-year financial data were not available for 2005.
} 
and the results indicate that the scales held together well. Cronbach's alpha for the impressiveness scale was .94, and the respectability scale had an overall alpha of .86 .

\section{Primary Analyses}

\section{Multiple Regression: Original Scale}

Two multiple regression analyses were conducted to determine the impact of the objective signals on the impressiveness and respectability ratings. For the first analysis, the hypothesized antecedents of organizational impressiveness were entered (revenue, stock price, media attention, and advertising budget), with impressiveness as the criterion variable. The overall regression equation was not significant $F(4,24)=1.88, p=.15$. However, when examining the relationship between the individual signals and impressiveness, a company's advertising budget and revenue were both significant predictors of impressiveness. Advertising accounted for $16 \%$ of the variance in impressiveness ratings, and revenue accounted for $17 \%$ of the variance in impressiveness. Media attention and stock price did not significantly predict impressiveness ratings. Bivariate correlations and beta weights for each of the signals of impressiveness can be found in Table 7. It should be noted that the beta weight for revenue is negative, indicating that companies with lower revenue were perceived to be more impressive than those with higher revenue.

For the second analysis, the number of SEC filings, presence or absence on Fortune Magazine's "Best companies to work for" listing (Levering \& Moskowitz, 2005), presence or absence on Business Ethics magazine's list of the best corporate citizens (Raths, 2006), product quality and value ratings, and charitable donations were evaluated as predictors of respectability. The linear combination of predictors was significantly related to respectability ratings, $F(6,18)=$ $2.70, p<.05$. Bivariate correlations between each predictor and respectability ratings, as well as 
beta weights for each predictor, can be found in Table 8 . When examining the individual predictors, only product quality was a significant predictor of respectability, accounting for $47 \%$ of the variance in respectability ratings.

More exploratory analyses were also conducted to determine whether relationships existed between the objective signals and impressiveness and respectability that differed from those hypothesized. A regression equation was computed that included all of the objective signals. When the regression was conducted with impressiveness as the dependent variable, the overall regression equation was significant $F(10,13)=3.22, p<.05$. Advertising budget remained a significant predictor of impressiveness in the new equation, accounting for $33 \%$ of the variance in impressiveness ratings. However, revenue no longer significantly predicted, and Fortune Magazine's "Best Company to Work for" rank, Business Ethics rank, and product quality ratings emerged as significant predictors of organizational impressiveness. Bivariate correlations between each predictor and impressiveness ratings, as well as beta weights for each predictor, can be found in Table 9. It should be noted that the beta weight for the Fortune rank is negative, indicating that companies included on the list were perceived to be less impressive than organizations that were not included in the Fortune ranking.

When the same regression equation with all organizational signals entered was conducted with respectability as the criterion, the overall regression equation was not a significant predictor of respectability $F(10,13)=1.35, p=.30$. Product quality ratings remained the only significant individual predictor of respectability.

Taken as a whole, these analyses suggest that, consistent with expectations, advertising (a signal of visibility) relates to job-seekers' impressions of prestige. Counter to expectations, revenue was negatively related to impressiveness, and the exploratory analyses unexpectedly 
revealed that the Fortune ranking of the best companies to work for was negatively related to impressiveness, and business ethics ranking and product/service quality perceptions were positively related to impressiveness ratings. Impressions of product/service quality appear to be the driver of respectability ratings for the present sample.

Multiple Regression: Unidimensional Symbolic Reputation Measure

Because impressiveness and respectability were so highly correlated in the present sample $(r=.77)$, the impressiveness and respectability scales were combined to create a single symbolic reputation measure for each of the companies. Cronbach's alpha for the combined reputation scale was .93 . A regression equation with the new symbolic reputation measure as the dependent variable was computed that included all of the objective signals. The overall regression equation was not significant $F(10,13)=2.19, \mathrm{p}=.09$. When examining the individual predictors, product quality was the only significant predictor of overall symbolic reputation. Bivariate correlations between each predictor and symbolic reputation ratings, as well as beta weights for each predictor, can be found in Table 10.

Multiple Regression: Revised Scales

Based on intercorrelations among items on the original impressiveness and respectability scales, highly overlapping items were deleted to create two more distinct scales. For the impressiveness scale, item one was deleted, resulting in a four item impressiveness measure with a Cronbach's alpha of .96. Three items (items one, three, and five) were deleted from the respectability scale, resulting in a two item respectability scale with a Cronbach's alpha of .55. The correlation between the revised impressiveness and respectability scales was .41. Correlations among all variables and the revised scales can be found in Table 11 . Table 12 contains the new average impressiveness and respectability ratings for each of the organizations, 
with t-values used to indicate whether an organization's impressiveness and respectability ratings significantly differed from one another. To correct for experiment wise error, a $99.9 \%$ confidence interval was used. Impressiveness and respectability scores differed significantly for $63 \%$ of the companies. Among the companies with significant differences between the new impressiveness and respectability scores, $63 \%$ of the companies scored higher on impressiveness than respectability, and $37 \%$ were viewed as more respectable than impressive.

Two multiple regression analyses were conducted to determine the impact of the objective signals on the revised impressiveness and respectability ratings. For the first analysis, revenue, stock price, media attention, and advertising budget were entered as predictors, with impressiveness as the criterion variable. The overall regression equation was not significant $F(4,24)=1.80, \mathrm{p}=.16$. However, when examining the relationship between the individual signals and impressiveness, a company's advertising budget was a significant predictor of impressiveness. Advertising accounted for $16 \%$ of the variance in impressiveness ratings. Media attention, stock price, and revenue did not significantly predict impressiveness ratings. Bivariate correlations and beta weights for each of the signals of impressiveness can be found in Table 13.

For the second analysis, the number of SEC filings, presence or absence on Fortune Magazine's “Best companies to work for" listing (Levering \& Moskowitz, 2005), presence or absence on Business Ethics magazine's list of the best corporate citizens (Raths, 2006), product quality and value ratings, and charitable donations were evaluated as predictors of the revised respectability scores. The linear combination of predictors was significantly related to respectability ratings, $F(6,18)=4.47, p<.01$. Bivariate correlations between each predictor and respectability ratings and beta weights for each predictor can be found in Table 14. When 
examining the individual predictors, only product quality was a significant predictor of respectability, accounting for $56 \%$ of the variance in respectability ratings.

As was the case with the original impressiveness and respectability scores, exploratory analyses were also conducted to determine whether relationships existed between the objective signals and the revised impressiveness and respectability scales that differed from those hypothesized. A regression equation was computed that included all of the objective signals. When the regression was conducted with impressiveness as the dependent variable, the overall regression equation was not significant $F(10,13)=2.38, p=.07$. When examining the individual predictors, advertising budget remained the only significant predictor of impressiveness in the new equation, accounting for $28 \%$ of the variance in impressiveness ratings.

When the same regression equation with all organizational signals entered was conducted with the revised respectability measure as the criterion, the overall regression equation was significant $F(10,13)=2.78, p<.05$. Product quality ratings remained the only significant individual predictor of respectability, and accounted for $47 \%$ of the variance in the new respectability scores. 


\section{DISCUSSION}

The purpose of this study was to examine the determinants of symbolic reputation, and specifically to examine the determinants of entry-level job seekers' ratings of organizational impressiveness and respectability. The two symbolic reputation factors and the new combined symbolic reputation measure will be considered individually.

Impressiveness

Revenue: One interesting finding is the negative weight of revenue on impressiveness ratings, indicating that in the present study, companies with lower revenue were perceived to be more impressive than companies with higher revenue. Although this finding should be interpreted with a degree of caution considering that the companies selected are generally all large, profitable companies, the discrepancy between the negative weight the present sample placed on revenue, compared with the strong positive weight previous research has found, is worth noting. Although financial performance generally has the greatest impact on business experts' ratings of corporate reputation (Fombrun \& Shanley, 1990; Brown \& Perry, 1994; Cable \& Graham, 2000), this does not appear to be the case with relatively naïve job seekers. One explanation for this contradiction is the fact that corporate giants such as WalMart carry a great deal of clout in the financial community, yet were not perceived to be impressive employers by the job-seekers. When Wal-Mart was removed from the data set, the relationship between revenue and impressiveness failed to reach significance $(p=.48)$, but the beta weight for revenue remained negative $(\beta=-.16)$. When the regression equation was computed with the revised impressiveness scale, the relationship between revenue and impressiveness was no longer significant (with Wal-Mart included in the data set $p=.06, \beta=-.38$, with Wal-Mart removed $p$ $=.68, \beta=-.10)$, but the negative relationship remained. 
Media attention: Objective media attention was not a significant predictor of organizational impressiveness. One possible reason for its lack of significant impact was that the present study looked at overall media attention, rather than separating positive and negative attention. It is possible that by looking at both positive and negative attention, negative media attention washed out any potential effects of positive media exposure. The relationship between media exposure and reputation is ambiguous and warrants future research; Fombrun and Shanley (1990) found that both positive and negative media attention negatively affected reputation perceptions, whereas the present study found no relationship. Another potential explanation for the lack of significance is that the present study looked at media attention in business news, rather than the popular press. Unlike financial experts who may be highly influenced by these sources (Fombrun \& Shanley, 1990; Dowling, 2004), the sample of undergraduates recruited for this study likely has limited exposure to business news, and may therefore be less affected by this source.

Advertising: One finding consistent with expectations and previous research was that adverting did have a significant impact on ratings of corporate impressiveness, such that companies perceived to be impressive tended to have a larger advertising budget. This supports the idea that visibility is an important component of organizational impressiveness, and illustrates the importance of advertising in reputation building. It also suggests that job seekers may be swayed by messages presented by the organization itself. In a study examining the relationship between market activities and application intentions, Collins and Stevens (2002) found that organizational attraction is highly influenced by advertising during the early recruitment phase. Participants in this study were more likely to apply to organizations if they could recall advertising or promotional material provided by the organization. The importance of 
advertising for reputation is also highlighted in Brady et al.'s (2005) finding that companies facing scandal or crisis are shying away from the traditional approach of lying low, and are instead launching advertising campaigns. Companies have found that advertising is an effective strategy for image restoration and counteracting negative press. In a Canadian study of corporate reputation to assess the general public's perceptions of companies, Dobson (2005) found that the companies with the most positive reputations advertised heavily. The findings of the present study, along with those of previous research, provide strong support for the importance of advertising for maintaining a positive reputation, both to job-seekers and to the general public. It would be interesting to dive deeper into the relationship between advertising and impressiveness by examining the venues in which the advertising takes place. For example, it is possible that advertising was a significant predictor in the present sample because the participants represent the target demographic for many of the companies selected. Advertising in business or financial journals may have a very different impact on impressiveness ratings than advertising in popular television shows.

Stock Price: Stock price was not a significant predictor of organizational impressiveness ratings. Previous research (focused on financial experts' opinions) found that stock price was an important predictor of reputation (Cable \& Graham, 2000; Brown \& Perry, 1994), but this did not hold for the present sample. This finding may illustrate the fact that naïve job seekers are unaware of financial indicators such as stock price, or do not see a connection between organizational impressiveness and stock value. Also, stock price was uncorrelated with revenue for the organizations included in this study, which complicates the assumption that stock price is a signal of financial performance for the present sample. 
Overall, these findings suggest that companies may have some control over the extent to which they are viewed as impressive; it was advertising, rather than stock price, or attention from outside media, which increased job seekers' perceptions of impressiveness. It is also important to note that the conventional belief that financial performance is the strongest reputation factor may not hold when the job seekers are not business or financial experts.

In the first set of exploratory analyses, where the constructs hypothesized to underlie respectability were also included as predictors of the original impressiveness scale, other interesting findings emerged. Advertising remained a significant predictor of impressiveness, and was joined by product quality ratings, presence on Business Ethic's list of the best corporate citizens, and Fortune's ranking of the best companies to work for (which negatively affected impressiveness perceptions).

Although the relationship between product quality ratings and impressiveness was far weaker than the relationship between product quality and respectability ratings, it did emerge as a significant predictor, indicating that companies providing high-quality goods are viewed as both impressive and respectable. This finding reinforces the importance of providing goods and services that the public views to be high quality in attracting employees.

The link between the Business Ethics rank and impressiveness was interesting, particularly considering that there was not a significant relationship between respectability and the Ethics rank. Rather than influencing perceptions of respectability, this information may have served only to increase the visibility of the organizations included, which influenced perceptions of impressiveness but not respectability. It is possible that the job seekers were unaware of the reasons an organization would be included or excluded from this list, and this information increased name recognition or familiarity with an organization, but did not serve as a mechanism 
for communicating information about corporate social responsibility. It is also possible that a third (unknown) variable is driving the relationship between impressiveness and the Business Ethics rank.

The negative effect the Fortune ranking had on impressiveness ratings is unexpected and difficult to explain. It is possible the result is simply an anomaly; the relationship barely reached significance $(p=.05)$ and the relatively low number of companies included on the list may also have affected results. Only nine of the thirty companies in this study were included in the rankings; the results may have differed if more of the organizations selected for inclusion in this study were included in the Fortune ranking.

It is important to note that, with the exception of advertising budget (which remained a significant predictor of impressiveness in all analyses), these results were not replicated when the exploratory analyses were re-run with the revised impressiveness measure. Further research is needed before any accurate conclusions about the relationship between impressiveness perceptions, product quality perceptions, and Business Ethics and Fortune rankings can be drawn.

It should be noted that there is a sizable portion of variance in the impressiveness ratings that remains unaccounted for. One potential untapped source of variance may lie in obtaining a measure of how "cool" or "hip" the companies are perceived to be. A possible objective signal for this "cool factor" that is untapped in the present sample may be market share, which would assess the dominance of a particular company's products or services within a specific industry. It is also possible that limitations in the objective measures led to the unexplained variance, such that the objective signals used as indicators of an organization's financial performance and visibility did not adequately capture the true construct. 


\section{Respectability}

The second symbolic reputation factor, respectability, was hypothesized to have three underlying constructs: responsibility to the community, responsibility to employees, and responsibility to the consumer. Each of these constructs will be considered separately. Responsibility to the Community: Neither of the community responsibility signals were significant predictors of respectability perceptions.

Charitable donations: An organization's level of charitable donations was not a significant predictor of organizational respectability. One possible reason for this is the intricacy involved in determining the total amount a company donates, making an accurate understanding of which organizations are the biggest donors difficult, if not impossible. Charitable donations are not consistently publicized by corporations, and some companies do not reveal their total giving to the public. Future research might focus on perceptions of charitable giving, rather than attempting to obtain financial data, to address this issue.

Business Ethics Rank: Whether or not an organization was included on Business Ethics magazine's list of the best corporate citizens did not have an effect on job seekers' respectability ratings, although, as discussed previously, it did affect impressiveness ratings using the original impressiveness measure.

Responsibility to Employees: Neither of the signals for responsibility to employees significantly predicted organizational respectability ratings, suggesting that new job seekers may be unaware of a corporation's treatment of its employees.

Fortune Magazine’s “Best Companies to Workfor” rank: An organization's presence on the annual ranking of the best companies to work for did not predict perceptions of organizational respectability, and negatively affected perceptions of impressiveness in the first 
set of exploratory analyses. It seems likely that this is not an information source the entry-level job seekers are aware of, or influenced by, when considering the respectability of organizations as potential employers.

SEC violations: SEC violations did not have a significant impact on respectability ratings. SEC filings are not widely publicized, and as was the case with the Fortune rankings, it seems likely that the job seekers were unaware of this information.

Responsibility to Consumers: Responsibility to consumers was the only construct hypothesized to underlie respectability that had a significant predictor of organizational respectability.

Product quality: Product quality ratings had a major impact on respectability ratings, and were in fact the only significant predictor of organizational respectability for both the original and revised measures of respectability, as well as the unidimensional reputation score. Job seekers viewed organizations that provide high-quality goods and services to be more respectable than organizations with lower quality offerings. This finding is supported by policy-capturing research evaluating the antecedents of unidimensional reputation perceptions among a similar sample of naïve job seekers (Cable \& Graham, 2000). Whether or not the organization provided products and services the job-seeker would be proud to endorse received the highest beta weight in the policy-capturing study, and accounted for $19 \%$ of the variance in reputation perceptions. It seems likely that the job seekers in the present sample, consisting of naïve, first-time job seekers, are more familiar with the products and services offered by the organizations than with more detailed business or financial data, and subsequently are most heavily influenced by this signal.

Product Value: Contrary to expectations, product value did not predict respectability ratings. One possible reason for this is that products consumers consider to be a good value may carry connotations of being cheap or 'low class' rather than respectable. 


\section{Dimensionality of Symbolic Reputation}

The scale used to measure perceptions of corporate impressiveness and respectability was adapted from previous research examining individual differences in the value placed on associating with impressive or respectable organizations (Highhouse et al., in press). In the original measure (Highhouse et al., in press), it was found that impressiveness and respectability were conceptually distinct subcomponents of symbolic reputation, but the two were highly correlated in the present study. Further revisions of the adapted scale may be warranted to create more conceptually distinct reputation factors. However, there may be other potential reasons for the high correlation between impressiveness and respectability. Because the sample consisted of naïve job seekers, only organizations that are very well known and that offer products and services undergraduate students are likely to have been exposed to were selected. Using a more diverse group of companies could have potentially alleviated the problems from the high correlation between impressiveness and respectability. The industry the companies belong to could also affect the impressiveness and respectability scores. Overall, among organizations that had significantly different impressiveness and respectability ratings, technology-oriented and automotive companies were viewed as more impressive than respectable, and retail organizations were rated as more respectable than impressive. There were also significant differences in overall impressiveness scores across sectors $(F(2,27)=4.08, p<.05)$. Technology-oriented companies $(M=3.91, S D=.41)$ were perceived to be significantly more impressive than retail organizations $(M=3.19, S D=.74)$. Perhaps focusing on companies from these industries would yield more distinct impressiveness and respectability ratings. Despite the problems associated with the intercorrelation of the scales, the results were largely unchanged when the scales were altered to 
reduce the intercorrelation; advertising budget and product quality ratings remained the major predictors of impressiveness and respectability for both the original and revised scales.

\section{General Discussion}

The results of the present study indicate that the determinants of relatively naïve job seekers' reputation perceptions may be very different than those of financial or business experts. The sources these raters attune to differed from the sources experts seem to weigh most heavily, such as financial performance. The organizations most appealing to naïve job seekers are those that are heavily advertised and provide goods or services consumers view as high quality. The results of the present study indicate that the reputation perceptions of naïve job seekers are highly consumer-driven. Advertising and product quality ratings were the two major predictors of impressiveness and respectability, and both are typically associated with consumers, rather than job seekers.

\section{Limitations and Future Research}

One major limitation of the study is that the sample consisted solely of undergraduate job seekers, and the results may not be generalizable to job seekers in other stages of their careers. However, first-time job seekers are an important segment of the job market, and their perceptions of impressiveness and respectability are as important as those of more experienced job seekers. Future research should replicate the present study with more experienced job seekers to see whether there are differences in reputation perceptions across different career stages.

Although it can be argued that this task does not realistically capture the manner in which job seekers consider various information sources to form a cohesive view of a company's symbolic reputation because the participants were not actually seeking out employment opportunities at the organizations they were rating, the task does mimic the approach many first- 
time job seekers take in apply for a job. Many job seekers, and particularly first time job seekers who lack the skills and experience that would allow them the luxury of selectively choosing among employers, "cast a wide net" during the initial phases of the job search process. During this initial phase, job seekers likely have relatively limited information about the companies they are applying to work for. Detailed information about specific companies is often not gathered until the pool has been narrowed down considerably and job-seekers are examining one or two options.

This study used objective indicators of subjective phenomenon, which is both a limitation and a strength. Most previous research has relied solely on subjective perceptions of reputation. This study used both subjective and objecting indicators to avoid the issue of common method variance and halo effects, but this may have come at the expense of gaining an accurate understanding of how naïve job seekers form impressions of organizational impressiveness and respectability. Many of the objective signals used in this research (stock price, revenue, Business Ethics) may have been more appropriate for gaining an understanding of experts' reputation perceptions. Perhaps subjective impressions (asking job-seekers about their perceptions of an organization's financial performance rather than obtaining stock price or revenue figures) would be more appropriate for this sample of job-seekers. Future research should attempt to replicate the present research using subjective rather than objective indicators.

The importance of advertising in the organizational attraction process is one finding that should be explored in further detail. For example, perhaps hypothesized indicators of respectability such as charitable donations and fair treatment of workers would have a stronger impact on reputation perceptions if this information were communicated more consistently and frequently to job-seekers by the organizations through advertising. 


\section{Implications}

Overall, the results suggest that the relationship between objective signals and reputation perceptions may be very different for naïve job seekers than for experts. These findings can have important implications for both job seekers and for organizations as they are designing recruitment strategies for entry-level employees. One important implication for entry-level or naïve job-seekers may lie in improving the way they seek out information about organizations. Job-seekers should be encouraged to seek out information beyond advertising that comes from the organization itself, or their own experiences with the company's product or services as they consider organizations as potential employers. For example, Fortune magazine's list of the 100 best companies to work for should be a source job-seekers highly value and take into account as they choose employment opportunities to pursue, but in the present sample, the ranking had no relationship with respectability and a negative relationship with impressiveness.

These data also provide valuable insights that can be used to tailor recruitment strategies to attract entry-level employees. Focusing on advertising and the quality of the products/services seems to be the most effective avenue for attracting naive job seekers. To increase the effectiveness of advertising, companies should incorporate other sources hypothesized to underlie reputation (Fortune Ranking, Business Ethics ranking, charitable donations) into their advertising instead of relying on job seekers to pursue these sources on their own. 


\section{REFERENCES}

Bannerjee, S., Gulas, C.S., \& Iyer, E. (1995). Shades of Green: A multidimensional analysis of environmental advertising. Journal of Advertising, 24, 21-31.

Bauer, T.N., \& Aiman-Smith, L. (1996). Green career choices: The influence of ecological stance on recruiting. Journal of Business and Psychology, 10, 445458.

Brady. D., Arndt., M., \& Barrett, A. (2005). When your name is mud, advertise. Business Week, 3941, 56-58.

Brown, B., \& Perry, S., (1994). Removing the financial performance halo from Fortune's most admired companies. Academy of Management Journal, 37, 13471359.

Cable, D.M, \& Graham, M.E. (2000). The determinants of job seekers' reputation perceptions. Journal of Organizational Behavior, 21, 929-947.

Cable, D.M., \& Turban, D.B. (2003). The value of organizational reputation in the recruitment context: A brand-equity perspective. Journal of Applied Social Psychology, 33, 2244-2266.

Cialdini, R.B., Borden, R.J, Thorne, A., Walker, M.R., Freeman, S., \& Sloan, L.R. (1976). Basking in reflected glory: Three (football) field studies. Journal of Personality and Social Psychology, 34, 366-375.

Collins, C.J., \& Stevens, C.K. (2002). The relationship between early recruitment activities and the application decisions of new labor market entrants: a brand equity approach to recruitment. Journal of Applied Psychology, 87, 1121-1133.

Dobson, S., (2005). The halo effect. Marketing Magazine, 110, 11-15. 
Dowling, G. (2004). Journalists' evaluation of corporate reputations. Corporate Reputation Review, 7, 196 - 205.

Dukerich, J.M., Golden, B.R., \& Shortell, S.M. (2002). Beauty is in the eye of the beholder: The impact of organizational identification, identity, and image on the cooperative behaviors of physicians. Administrative Science Quarterly, 47, 507-533.

Dutton, J.E., Dukerich, J.M., \& Harquail, C.V. (1994). Organizational images and member identification. Administrative Science Quarterly, 39, 239-263.

EDGAR Online (U.S. Securities and Exchange Commission). http://www.sec.gov/edgar.shtml

Fombrun, C.J., \& Shanley, M. (1990). What's in a name? Reputation building and corporate strategy. Academy of Management Journal, 33, 233-258.

Fombrun, C.J. (1996). Reputation: Realizing value from the corporate image. Boston: Harvard Business School Press.

Google News. http://news.google.com/nwshp?hl=en\&tab=wn\&q=.

Harris Interactive. www.harrisinteractive.com.

Highhouse, S., Lievins, F., \& Sinar, E. (2003). Measuring attraction to organizations. Educational and Psychological Measurement, 63, 1-16.

Highhouse, S., Zickar, M. Thorsteinson, T., Stierwalt, S., \& Slaughter, J. (1999). Assessing company employment image: An example in the fast food industry. Personnel Psychology, 52, 151-169.

Highhouse, S., Thornbury, E.E., \& Little, I.S. (In press). Social-identity functions of attraction to organizations. Organizational Behavior and Human Decision Processes.

Katz, D., (1960). The functional approach to the study of attitudes. Public Opinion Quarterly, 24, 163-204. 
Keller, K.L. (1993). Conceptualizing, measuring, and managing customer-based brand equity. Journal of Marketing, 57, 1-22.

Knoop, R. (1994). Organizational commitment and individual values. Perceptual and Motor Skills, 78, 200-202.

Lease, A.M., Musgrove, K.T. \& Axelrod, J.L. (2002). Dimensions of social status in preadolescent peer groups: likeability, perceived popularity, and social dominance. Social Development, 11, 508-533.

Levering, R., \& Moskowitz, M. (2005. January 24). 100 best companies to work for. Fortune, 151, 72-90.

Lievins, F., \& Highhouse, S. (2003). The relation of instrumental and symbolic attributes to a company's attractiveness as an employer. Personnel Psychology, 56, 75-102.

Lievens, F. \& Van Hoye, G. (2005). Examining the relationship between employer knowledge dimensions and organizational attractiveness: An application in a military context. Journal of Occupational and Organizational Psychology,

Lewis, S. (2001). Measuring corporate reputation. Corporate Communications, 6, 31-35.

Montgomery, D.B., \& Ramus, C.A. (2003). Corporate Social Responsibility Reputation Effects on MBA Job Choice. In G. Papanikos and C. Veloutsou (Eds.), Global Issues of Business (Vol. 2). Athens Institute for Education and Research.

Park, D., \& Berger, B.K. (2005). The presentation of CEOs in the press, 1990-2000: Increasing salience, positive valence, and a focus on competency and personal dimensions of image. Journal of Public Relations Research, 16, 93-125.

Pickett, J.P. (Ed.) The American Heritage Dictionary of the English Language (4 ${ }^{\text {th }}$ ed.). Boston: Houghton Mifflin, 2000. 
Raths. D. (2006 Spring). 100 best corporate citizens 2006. Business Ethics, 20, 22-24.

Scott, S.G., \& Lane, V.R. (2000). A stakeholder approach to organizational identity. Academy of Management Review, 25, 43-62.

Slaughter, J.E., Zickar, M., Highhouse, S., Mohr, D.C., Steinbrenner, D., \& O’Connor, J. (2004). Personality trait inferences about organizations: Development of a measure and assessment of construct validity. Journal of Applied Psychology, 89, 85-103.

Turban, D.B. \& Cable, D.M (2003). Firm reputation and applicant pool characteristics. Journal of Organizational Behavior, 24, 733-751.

Turban, D.B. \& Greening, D.W. (1996). Corporate social performance and organizational attractiveness to prospective employees. Academy of Management Journal, 40, 658-672. 


\section{APPENDIX A}

IMPRESSIVENESS AND RESPECTABILITY SCALE.

Impressiveness

1. This company is popular and prestigious.

2. Working for this company would make employees seem impressive to others.

3. Working for this company is perceived to be impressive.

4. Working for this company would impress employees' family and friends

5. Strangers would be impressed if employees of this company told them where they work.

\section{Respectability}

1. Employees can be proud to work for this company.

2. This company has a bad image.

3. This company has an honorable reputation in the community.

4. This company is scandal-free.

5. This is a respectable company. 


\section{APPENDIX B}

SELECTED COMPANIES

Company Reputation Quotient

Sony

Microsoft

Dell

IBM

Apple

Hewlett-Packard/Compaq

Honda

Toyota

Ford Motor Co.

General Motors

Daimler Chrysler

Lowe's

Home Depot

Starbucks

Target

Wal-Mart

Sears/K-Mart

Best Buy

J.C. Penney

McDonald's

Coca-Cola Company

United Parcel Service (UPS)

General Mills

Nike

Verizon

Sprint

PepsiCo

FedEx Corporation

Proctor \& Gamble

Walt Disney

Southwest Airlines
75.75

78.11

75.73

73.42

70.59

69.44

75.60

77.27

66.14

66.07

64.47

75.43

76.50

72.93

71.83

69.99

65.26

69.74

68.81

66.83

79.69

79.37

78.03

72.11

67.01

61.01

75.26

77.79

75.91

75.88

73.20 


\section{APPENDIX C}

PRODUCT QUALITY AND VALUE SCALE.

The products/services offered by this company are very high quality

Strongly Agree

Strongly Disagree

1

2

3

4

5

The products/services offered by this company are an excellent value

Strongly Agree

Strongly Disagree

1

2

3

4

5 
Table 1. Summary of Previous Reputation Determinants

Source

Determinants of Reputation

Fortune Magazine

Cable \& Graham, 2000

Park \& Berger, 2004

Dowling, 2004

Fombrun, 1996 (RQ)

Fombrun \& Shanley, 1990

Dobson, 2005

Brady, Arndt, \& Barrett, 2005

Bannerjee, Gulas, \& Iyer, 1995

Bauer \& Aiman-Smith, 1996

Turban \& Greening, 1996
Quality of management, quality of products or services, value as a long term investment, innovativeness, soundness of financial position, ability to attract, develop, and keep talented people, responsibility to the community and environment, wise use of corporate assets

Industry in which the firm operates, opportunities for employee development, organizational culture, familiarity with the organization, the length of time the organization has been in existence, the size and location of the organization, workforce demographics, pay level, and the profitability of the organization

CEO Visibility

Social accountability (corporate ethics and citizenship), corporate capability (leadership, innovativeness, financial performance), media relations (accessibility), market presence (familiarity, sector leadership), and corporate personality

Vision and leadership, emotional appeal, financial performance, workplace environment, social responsibility, and products and services

Sector, firm size, economic performance, riskiness, level of institutional stock ownership, media exposure, advertising, and charitable expenditures

Advertising

Advertising

Environmental stance

Environmental stance

Environmental stance, charitable donations/community activism, history of scandal, labor relations 
Table 2. Proposed Model of Constructs Underlying Symbolic Reputation

Operationalized Constructs/ Underlying Constructs Symbolic Reputation Factor Signal

Advertising Budget $\quad$ Visibility

Media Attention

Stock Price

Financial Performance

Impressiveness

Revenue

Business Ethics Rank

Responsibility to Community

Charitable Do nations

Fortune "Best Companies to Responsibility to Employees

Work For" ranking

SEC Violations

Product Quality Rating Responsibility to Customers

Product Value Rating
Respectability 
Table 3. Objective Signals

\begin{tabular}{|c|c|c|c|c|c|c|c|c|}
\hline Company & Media(5/15) & Stock (5/22) & Revenue (mil) & Advertising & SEC & Charity & \begin{tabular}{|l} 
Business \\
Ethics
\end{tabular} & Fortune \\
\hline $\begin{array}{r}\text { Sony } \\
\text { Corporation }\end{array}$ & 23700 & 45.49 & 13769 & 3361 & 160 & 30167249 & 0 & 0 \\
\hline Microsoft & 62300 & 22.88 & 39788 & 1060 & 1058 & 410700000 & 0 & 1 \\
\hline Dell & 11200 & 24.38 & 49205 & 467 & 776 & 1978490 & 1 & 0 \\
\hline IBM & 12200 & 80.02 & 91134 & 1284 & 352 & 115499000 & 1 & 0 \\
\hline Apple & 25600 & 63.38 & 13931 & 287 & 441 & & 1 & 0 \\
\hline HP/Compaq & 5908 & 32.18 & 86696 & 1100 & 1103 & 143700000 & 1 & 0 \\
\hline Honda & 14100 & 33.81 & 80549 & 2300 & 121 & & 0 & 0 \\
\hline Toyota & 15600 & 107.63 & 172749 & 3536 & 95 & 40000000 & 0 & 0 \\
\hline Ford Motor & 52500 & 6.9 & 17710 & 5000 & 1142 & 100900000 & 0 & 0 \\
\hline $\begin{array}{r}\text { General } \\
\text { Motors }\end{array}$ & 14300 & 24.44 & 192604 & 5800 & 1542 & 224800000 & 0 & 0 \\
\hline $\begin{array}{r}\text { Daimler } \\
\text { Chrysler }\end{array}$ & 5030 & 51.16 & 117191 & 1665 & 127 & & 0 & 0 \\
\hline Lowe's & 3430 & 59.82 & 43243 & 812 & 601 & 37000000 & 0 & 0 \\
\hline Home Depot & 5950 & 38.49 & 81511 & 1000 & 672 & 40600000 & 0 & 0 \\
\hline Starbucks & 5670 & 36.23 & 6369 & 87.7 & 367 & 30300000 & 1 & 1 \\
\hline Target & 61700 & 49.13 & 51271 & 1028 & 488 & 88806318 & 0 & 0 \\
\hline Wal-Mart & 22100 & 47.35 & 285222 & 1400 & 596 & 226245741 & 0 & 0 \\
\hline Sears/Kmart & 4493 & 158.35 & & & 232 & & 0 & 0 \\
\hline Best Buy & 24200 & 52.26 & 27443 & 712 & 587 & 18875759 & 0 & 0 \\
\hline J.C. Penny & 1509 & 62.09 & 18781 & 1202 & 211 & 13144837 & 0 & 0 \\
\hline McDonalds & 9310 & 34.03 & 20460 & 734 & 667 & 12800000 & 0 & 0 \\
\hline Coca-Cola & 8930 & 43.6 & 23104 & 2475 & 547 & 67521254 & 0 & 0 \\
\hline UPS & 18300 & 80.3 & 42581 & & 810 & 40900000 & 1 & 0 \\
\hline General Mills & 2660 & 49.76 & 11244 & 477 & 607 & 42400000 & 1 & 1 \\
\hline FedEx & 2500 & 110.05 & 29363 & 326 & 385 & 13000000 & 0 & 1 \\
\hline $\begin{array}{r}\text { Procter \& } \\
\text { Gamble } \\
\end{array}$ & 233 & 54.28 & 56741 & 5917 & 1029 & 23158523 & 1 & 1 \\
\hline Walt Disney & 15800 & 30 & 31944 & 2900 & 594 & 165317242 & 0 & 0 \\
\hline PepsiCo & 6720 & 59.27 & 32562 & 1800 & 590 & 21908717 & 1 & 0 \\
\hline $\begin{array}{r}\text { Southwest } \\
\text { Airlines }\end{array}$ & 2350 & 15.65 & 7584 & 173 & 347 & & 1 & 0 \\
\hline Nike & 4230 & 77.98 & 13739 & 1600 & 755 & 29000000 & 1 & 0 \\
\hline Verizon & 13900 & 30.79 & 75112 & 1914 & 1805 & 71437000 & 0 & 0 \\
\hline Sprint & 13400 & 22.16 & 22328 & 1400 & 1108 & 5200000 & 0 & 0 \\
\hline
\end{tabular}


Table 4. Mean Product Quality and Value Ratings

\begin{tabular}{|c|c|c|}
\hline Company & Quality & Value \\
\hline Sony Corporation & 3.95 & 3.70 \\
\hline Microsoft & 4.10 & 3.76 \\
\hline Dell & 3.60 & 3.71 \\
\hline IBM & 3.33 & 3.27 \\
\hline Apple & 3.38 & 3.09 \\
\hline HP/Compaq & 3.43 & 3.33 \\
\hline Honda & 3.76 & 3.79 \\
\hline Toyota & 3.40 & 3.42 \\
\hline Ford Motor Co. & 3.25 & 3.23 \\
\hline General Motors & 3.56 & 3.50 \\
\hline Daimler Chrysler & 3.41 & 3.32 \\
\hline Lowe's & 3.54 & 3.45 \\
\hline Home Depot & 3.86 & 3.70 \\
\hline Starbucks & 3.78 & 2.99 \\
\hline Target & 3.80 & 4.06 \\
\hline Wal-Mart & 2.75 & 3.70 \\
\hline \multicolumn{3}{|l|}{ Sears/Kmart } \\
\hline Best Buy & 4.06 & 3.70 \\
\hline J.C. Penny & 3.30 & 3.48 \\
\hline McDonalds & 2.34 & 3.36 \\
\hline Coca-Cola & 3.52 & 3.66 \\
\hline UPS & 3.79 & 3.60 \\
\hline General Mills & 3.76 & 3.61 \\
\hline FedEx & 3.75 & 3.64 \\
\hline Procter \& Gamble & 3.78 & 3.65 \\
\hline Walt Disney & 4.01 & 3.34 \\
\hline PepsiCo & 3.82 & 3.66 \\
\hline Southwest Airlines & 3.39 & 3.33 \\
\hline Nike & 3.77 & 3.14 \\
\hline Verizon & 3.55 & 3.31 \\
\hline Sprint & 3.05 & 2.96 \\
\hline
\end{tabular}


Table 5. Mean Impressiveness and Respectability Scores: Original Scale

\begin{tabular}{|c|c|c|c|}
\hline Company & Impressiveness & Respectability & t-value \\
\hline Sony Corporation & 4.42 & 4.01 & $5.29^{\star}$ \\
\hline Microsoft & 4.26 & 3.83 & $3.21^{*}$ \\
\hline Dell & 4.33 & 3.91 & $4.58^{*}$ \\
\hline IBM & 3.88 & 3.71 & 1.36 \\
\hline Apple & 4.21 & 3.81 & $3.54^{*}$ \\
\hline HP/Compaq & 3.52 & 3.57 & -.45 \\
\hline Honda & 3.89 & 3.67 & $2.34^{*}$ \\
\hline Toyota & 3.56 & 3.64 & -.75 \\
\hline Ford Motor Co. & 3.92 & 3.67 & 1.57 \\
\hline General Motors & 3.58 & 3.46 & 1.13 \\
\hline Daimler Chrysler & 3.79 & 3.59 & $2.84^{\star}$ \\
\hline Lowe's & 2.79 & 3.48 & $-4.72^{*}$ \\
\hline Home Depot & 3.30 & 3.90 & $-4.64^{*}$ \\
\hline Starbucks & 2.96 & 3.68 & $-3.81^{*}$ \\
\hline Target & 3.02 & 3.50 & $-2.53^{*}$ \\
\hline Wal-Mart & 2.29 & 2.52 & -1.28 \\
\hline Best Buy & 3.18 & 2.52 & -1.24 \\
\hline J.C. Penny & 3.11 & 3.56 & $-2.61^{*}$ \\
\hline McDonalds & 1.96 & 1.95 & 1.00 \\
\hline Coca-Cola & 3.80 & 3.71 & .70 \\
\hline UPS & 3.53 & 3.70 & -1.16 \\
\hline General Mills & 3.68 & 3.77 & -.80 \\
\hline FedEx & 3.35 & 3.60 & -1.69 \\
\hline Procter \& Gamble & 3.84 & 3.35 & $3.21^{\star}$ \\
\hline Walt Disney & 4.26 & 3.96 & $2.48^{*}$ \\
\hline PepsiCo & 3.99 & 3.83 & 1.25 \\
\hline Southwest Airlines & 3.61 & 3.43 & $2.27^{\star}$ \\
\hline Nike & 4.29 & 3.73 & $3.12^{\star}$ \\
\hline Verizon & 3.49 & 3.58 & -.76 \\
\hline Sprint & 3.70 & 3.44 & $2.27^{\star}$ \\
\hline
\end{tabular}


Table 6. Signal Correlations

\begin{tabular}{|c|c|c|c|c|c|c|c|c|c|c|c|c|}
\hline & Media & Advertise & Stock & Revenue & Ethics & Charity & Fortun & $e \mathrm{SEC}$ & Quality & Value & Impressiveness & Respectability \\
\hline Media & & .12 & -.26 & .02 & -.32 & $.55^{*}$ & .08 & .17 & .14 & .30 & .12 & .02 \\
\hline Advertising & & - & -.12 & .30 & -.21 & .14 & .24 & .33 & .07 & .07 & .28 & .11 \\
\hline Stock & & & - & .10 & .12 & -.31 & -.05 & $-.45^{*}$ & .10 & .07 & -.06 & .06 \\
\hline Revenue & & & & - & -.26 & $.43 *$ & .00 & .09 & -.30 & .18 & -.29 & -.26 \\
\hline Ethics Rank & & & & & - & -.25 & .26 & .00 & .12 & -.25 & .29 & .25 \\
\hline Charity & & & & & & - & $.42 *$ & .31 & .10 & .19 & .1 & .04 \\
\hline Fortune Rank & & & & & & & - & .30 & .14 & -.10 & .09 & .13 \\
\hline SEC Filings & & & & & & & & - & -.03 & -.14 & .04 & -.06 \\
\hline Quality Ratings & & & & & & & & & - & $.37 *$ & $.56^{*}$ & $.61 *$ \\
\hline Value Ratings & & & & & & & & & & - & -.06 & -.03 \\
\hline Impressiveness & & & & & & & & & & & - & $.77 *$ \\
\hline Respectability & & & & & & & & & & & & - \\
\hline
\end{tabular}

$* p<.05$ 
Table 7. Impressiveness Beta Weights and Correlations

\begin{tabular}{lcccc}
\hline Organizational Signal & $B$ & $S E B$ & $\beta$ & Correlation with Impressiveness \\
\hline Revenue & .00 & .00 & $-.42^{*}$ & -.29 \\
Stock Price & .00 & .00 & .07 & -.06 \\
Media Exposure & .00 & .00 & .10 & .12 \\
Advertising Budget & .00 & .00 & $.40^{*}$ & .28 \\
\hline & & & & \\
$* p<.05$ & & & &
\end{tabular}


Table 8. Respectability Beta Weights and Correlations

\begin{tabular}{lcccc} 
Organizational Signal & $B$ & $S E B$ & $\beta$ & Correlation with Respectability \\
\hline Business Ethics & .13 & .22 & .13 & .28 \\
Charitable Donations & .00 & .00 & .09 & .04 \\
Fortune Ranking & -.03 & .25 & -.03 & .16 \\
SEC Violations & .00 & .00 & -.07 & -.03 \\
Product Quality & .82 & .23 & $.68^{*}$ & .63 \\
Product Value & -.48 & .38 & -.26 & -.02 \\
\hline
\end{tabular}

$* p<.01$ 
Table 9. Exploratory Impressiveness Beta Weights and Correlations

\begin{tabular}{lcccc} 
Organizational Signal & $B$ & $S E B$ & $\beta$ & Correlation with Impressiveness \\
\hline Business Ethics & .84 & .32 & $.64^{*}$ & .30 \\
Charitable Donations & .00 & .00 & .45 & .11 \\
Fortune Ranking & -.73 & .33 & $-.55^{*}$ & .18 \\
SEC Violations & .00 & .00 & -.06 & .11 \\
Product Quality & .67 & .30 & $.44^{*}$ & .62 \\
Product Value & -.57 & .46 & -.24 & .00 \\
Revenue & .00 & .00 & -.31 & -.30 \\
Stock Price & .00 & .00 & .08 & -.05 \\
Media Exposure & .00 & .00 & .15 & .11 \\
Advertising Budget & .00 & .00 & $.58^{* *}$ & .33 \\
\hline
\end{tabular}

$$
\begin{array}{r}
* p<.05 \\
* * p<.01
\end{array}
$$


Table 10. Unidimensional Symbolic Reputation Beta Weights and Correlations

\begin{tabular}{lcccc} 
Organizational Signal & $B$ & $S E B$ & $\beta$ & Correlation with Reputation \\
\hline Business Ethics & .44 & .29 & .42 & .37 \\
Charitable Donations & .00 & .00 & .10 & .03 \\
Fortune Ranking & -.24 & .30 & -.23 & .10 \\
SEC Violations & .00 & .00 & .02 & -.04 \\
Product Quality & .72 & .27 & $.59 *$ & .61 \\
Product Value & -.35 & .42 & -.18 & -.03 \\
Revenue & .00 & .00 & -.14 & -.33 \\
Stock Price & .00 & .00 & .02 & .03 \\
Media Exposure & .00 & .00 & .20 & .07 \\
Advertising Budget & .00 & .00 & .32 & \\
& & & & \\
\hline
\end{tabular}

$* p<.05$ 
Table 11. Signal Correlations: Revised Scale

\begin{tabular}{|c|c|c|c|c|c|c|c|c|c|c|c|c|}
\hline & Media & Advertise & Stock & Revenue & Ethics & Charity & Fortun & $e$ SEC & Quality & Value & Impressiveness & Respectability \\
\hline Media & & .12 & -.26 & .02 & -.32 & $.55^{*}$ & .08 & .17 & .14 & .30 & .11 & -.08 \\
\hline Advertising & & - & -.12 & .30 & -.21 & .14 & .24 & .33 & .07 & .07 & .30 & -.14 \\
\hline Stock & & & - & .10 & .12 & -.31 & -.05 & $-.45^{*}$ & .10 & .07 & -.15 & .14 \\
\hline Revenue & & & & - & -.26 & $.43^{*}$ & .00 & .09 & -.30 & .18 & -.26 & $-.55^{*}$ \\
\hline Ethics Rank & & & & & - & -.25 & .26 & .00 & .12 & -.25 & .27 & .12 \\
\hline Charity & & & & & & - & $.42 *$ & .31 & .10 & .19 & .09 & -.28 \\
\hline Fortune Rank & & & & & & & - & .30 & .14 & -.10 & -.01 & .04 \\
\hline SEC Filings & & & & & & & & - & -.03 & -.14 & .06 & -.23 \\
\hline Quality Ratings & & & & & & & & & - & $.37 *$ & $.49 *$ & $.63 *$ \\
\hline Value Ratings & & & & & & & & & & - & -.10 & .02 \\
\hline Impressiveness & & & & & & & & & & & - & $.41 *$ \\
\hline Respectability & & & & & & & & & & & & - \\
\hline
\end{tabular}

$* p<.05$ 
Table 12. Mean Impressiveness and Respectability Scores: Revised Scale

\begin{tabular}{|c|c|c|c|}
\hline Company & Impressiveness & Respectability & t-value \\
\hline Sony Corporation & 4.41 & 3.81 & $4.55^{\star}$ \\
\hline Microsoft & 4.21 & 3.43 & $4.27^{\star}$ \\
\hline Dell & 4.25 & 3.69 & $4.69^{*}$ \\
\hline IBM & 3.85 & 3.55 & 1.77 \\
\hline Apple & 4.16 & 3.55 & $3.55^{\star}$ \\
\hline HP/Compaq & 3.45 & 3.40 & 0.31 \\
\hline Honda & 3.81 & 3.52 & $2.52^{*}$ \\
\hline Toyota & 3.48 & 3.45 & 0.19 \\
\hline Ford Motor Co. & 3.86 & 3.45 & 1.95 \\
\hline General Motors & 3.51 & 3.30 & 1.74 \\
\hline Daimler Chrysler & 3.74 & 3.38 & $4.56^{\star}$ \\
\hline Lowe's & 2.64 & 3.60 & $-5.75^{\star}$ \\
\hline Home Depot & 3.90 & 3.30 & $4.64^{*}$ \\
\hline Starbucks & 2.61 & 3.78 & $-4.11^{*}$ \\
\hline Target & 2.80 & 3.45 & $-2.58^{*}$ \\
\hline Wal-Mart & 1.98 & 2.50 & $-2.50^{*}$ \\
\hline Best Buy & 3.04 & 3.38 & -1.89 \\
\hline J.C. Penny & 2.98 & 3.57 & $-2.58^{*}$ \\
\hline McDonalds & 1.69 & 3.08 & $-6.67^{\star}$ \\
\hline Coca-Cola & 3.66 & 3.50 & 1.05 \\
\hline UPS & 3.38 & 3.55 & -0.85 \\
\hline General Mills & 3.60 & 3.64 & -.27 \\
\hline FedEx & 3.24 & 3.65 & $-2.24^{*}$ \\
\hline Procter \& Gamble & 3.79 & 3.12 & $3.00^{*}$ \\
\hline Walt Disney & 4.19 & 3.75 & $2.79^{\star}$ \\
\hline PepsiCo & 3.87 & 3.64 & 1.37 \\
\hline Southwest Airlines & 3.58 & 3.20 & $3.74^{\star}$ \\
\hline Nike & 4.17 & 3.41 & $3.37^{\star}$ \\
\hline Verizon & 3.30 & 3.43 & -0.70 \\
\hline Sprint & 3.63 & 3.21 & $2.92^{*}$ \\
\hline
\end{tabular}

$* p<.05$ 
Table 13. Revised Impressiveness Beta Weights and Correlations

\begin{tabular}{lcccc}
\hline Organizational Signal & $B$ & $S E B$ & $\beta$ & Correlation with Impressiveness \\
\hline Revenue & .00 & .00 & -.38 & -.26 \\
Stock Price & .00 & .01 & -.04 & -.15 \\
Media Exposure & .00 & .00 & .06 & .11 \\
Advertising Budget & .00 & .00 & $.40 *$ & .30 \\
\hline & & & & \\
$* p<.05$ & & & &
\end{tabular}


Table 14. Revised Respectability Beta Weights and Correlations

\begin{tabular}{lrrrc} 
Organizational Signal & $B$ & $S E B$ & $\beta$ & Correlation with Respectability \\
\hline Business Ethics & -.08 & .67 & -.14 & .12 \\
Charitable Donations & .00 & .11 & -.33 & -.28 \\
Fortune Ranking & .07 & .00 & .12 & .04 \\
SEC Violations & .00 & .12 & -.22 & -.23 \\
Product Quality & .52 & .12 & $.75^{*}$ & .63 \\
Product Value & -.25 & .19 & -.23 & .02 \\
\hline
\end{tabular}

$* p<.01$ 
Figure 1. Relationship between Market Signals, Symbolic Inferences, and Attraction

\begin{tabular}{|c|c|c|c|}
\hline Market Signal & Symbo & erence & $\begin{array}{l}\text { Function of } \\
\text { Attraction }\end{array}$ \\
\hline $\begin{array}{l}\text { Compensation Leader } \\
\text { Fortune Ranking } \\
\text { Progressive } \\
\text { Technology }\end{array}$ & $\begin{array}{l}\text { Aggressive } \\
\text { Dominant } \\
\text { Innovative }\end{array}$ & $\begin{array}{l}\text { Impressive } \\
\text { Company }\end{array}$ & Social Adjustment \\
\hline $\begin{array}{l}\text { Socially Responsible } \\
\text { Family-Friendly } \\
\text { Policies } \\
\text { Principled Leader }\end{array}$ & $\begin{array}{l}\text { Sincere } \\
\text { Empathic } \\
\text { Fair \& Ethical }\end{array}$ & $\begin{array}{l}\text { Respectable } \\
\text { Company }\end{array}$ & Value Expression \\
\hline
\end{tabular}

